\title{
Correlation of Grading of Esophageal Varices with Child Turcotte Pugh Class in Patients of Liver Cirrhosis
}

\author{
Shrestha $A^{1}$, Khadka $D^{2}$, Shrestha $R^{3}$
}

\begin{abstract}
Background: Majority of cirrhotic patients develop varices over their lifetime and it is anticipated that roughly one third of varices will develop bleeding. Child Turcotte Pugh (CTP) class predicts the risk of variceal bleeding and has been used as a prognostic tool in patients of liver cirrhosis. Objective: To correlate grade of esophageal varices in Upper Gastrointestinal endoscopy with Child Turcotte Pugh class in patients of liver cirrhosis. Material and method: This is a cross sectional descriptive study conducted in the department of medicine of NGMCTH, Kohalpur between December 2017 to November 2018. A total of 97 patients were included in the study who were diagnosed as cirrhosis of liver clinically and radiologically. Patient were classified into CTP class A, B and C according to CTP score. UGl endoscopy was performed and endoscopic grading of esophageal varices were correlated with CTP class and the data were recorded and analysed. Result: Mean of patients was 50 years. Among 97 patients, $30(30.9 \%)$ were in CTP class A, 30 (30.9\%) in CTP class B and 37 (38.1\%) were in CTP class C. 25 (25.8\%) had small varices, 50 (51.5\%) had large varices with red color sign, $20(20.6 \%)$ had large varices without red color sign and $2(2.1 \%)$ had no varices. Most of the patients in CTP class B and C had large varices with red color sign whereas CTP class A had small varices. Conclusion: The cirrhotic patients in CTP class B and C have large varices with red color sign and have more chances of bleeding. Hence, routine screening is indicated to determine the presence of varices. Porphylactic therapy after identifying large varices will decrease the incidence of bleeding leading to reduction in mortality rate.
\end{abstract}

Key words: Child turcotte pugh class, cirrhosis, red color sign, sophageal varices

\section{INTRODUCTION}

Chronic liver disease is a process of progressive destruction and regeneration of liver parenchyma leading to fibrosis and cirrhosis ${ }^{1}$. Portal hypertension is the significant complicating feature of decompensated cirrhosis and is responsible for the development of esophageal varices ${ }^{2}$.

Over the last decade, it has become common practice to screen known cirrhosis to look for varices. It is estimated that the majority of cirrhotic patients develop varices over their lifetime. It is anticipated that roughly $1 / 3^{\text {rd }}$ of the varices will develop bleeding. Several factors predict the risk of bleeding like severity of cirrhosis (Child Pugh Class, MELD score), size of varices, location of varices, certain endoscopic stigmata like red wale sign (red color sign).

Child Pugh classification is a reliable staging system of cirrhosis with a scoring system of 5-15. Score of 5 and 6 Child Pugh class A (compensated cirrhosis), score of 7-9 indicating class B and 10-15 indicating class C. Child Pugh score is a reliable predictor

\footnotetext{
1. Dr. Anil Shrestha

2. Dr. Dipendra Khadka

3. Dr. Richa Shrestha
}

Address for correspondence:

Dr. Anil Shrestha

Department of Medicine

Nepalgunj Medical College Teaching Hospital

Kohalpur, Banke, Nepal

Email: shtanil4@gmail.com of survival in many liver disease and predicts the likelihood of bleeding from varices. In Child Pugh A esophageal varices are present in $40 \%$ whereas they are present in $85 \%$ in Child Pugh C. Hence Child Pugh grading correlates with presence of esophageal varices. Depending upon Child Pugh grade and comorbidities, mortality from single episode of variceal bleeding varies from $30 \%-50 \%$. Beta blocker therapy or endoscopic band ligation (EBL) is performed for primary as well as secondary prevention of variceal bleeding whereas EBL is also the treatment of choice for acute variceal bleeding.

Studies about the correlation of esophageal varices with severity of liver disease have been done in Kathmandu (Nepal), western countries, India, Pakistan and Bangladesh but not in western Nepal though cirrhosis of liver is not an uncommon disease in this region. Hence this study has been carried out.

\section{MATERIAL AND METHODS}

This is a cross-sectional descriptive study conducted in 97 patients who were admitted as cirrhosis of liver in medical units of NGMCTH, Kohalpur from December 2017 to November 2018. Informed consent of the patient and permission from Institutional review Committee (IRC) of the hospital was also obtained. A detailed clinical history was recorded regarding age, sex, symptoms like jaundice, distension of abdomen, hematemesis and malena. All patients underwent complete clinical examination including detailed examination of gastrointestinal system. Routine biochemical investigation, liver function test was done in every patient. Every recruited patient underwent ultrasonography. Thus cirrhosis of liver was 
diagnosed clinically and radiologically. Hemodynamically unstable cirrhotic patients, Hepatocellular carcinoma (HCC) and age more than 80 years were excluded from the study.

All cases of cirrhosis of liver were classified into A, B and C according to Child Pugh score. (Table I).

\begin{tabular}{|l|c|c|c|}
\hline & 1 point & 2 point & 3 point \\
\hline Serum Bilirubin (mg/dl) & $<2.0$ & $2.0-3.0$ & $>3.0$ \\
\hline Serum Albumin (g/dl) & $>3.5$ & $3.0-3.5$ & \\
\hline $\begin{array}{l}\text { Prothrombin time } \\
\text { (seconds prolonged) }\end{array}$ & $<4$ & $4-6$ & \\
\hline Ascitis & None & $\begin{array}{c}\text { Easily } \\
\text { controlled }\end{array}$ & $\begin{array}{c}\text { Poorly } \\
\text { controlled }\end{array}$ \\
\hline Encephalopathy & None & Minimal & Advanced \\
\hline
\end{tabular}

Table I: Child-Pugh classification of the severity of cirrhosis
All patients were subjected to upper gastrointestinal (UGI) endoscopy after an overnight fast of 12 hours and varices were graded according to size into small $(\leq 5 \mathrm{~mm})$ and large $(>5 \mathrm{~mm})^{5}$. Large varices were further categorized into varices with red color sign and without red color sign. Data were analysed using standard statistical method including SPSS 20.0.

\section{RESULT}

Total number of 97 patients with the diagnosis of cirrhosis of liver were recruited in the study. Among them majority of patients were between $40-60$ years of age $(71.1 \%)$ and mean age was 50 years. In male it was 49 years and in female 53 years. 81 patients (83.5\%) were male and $16(16.5 \%)$ were female. Out of 97 patients, 33 (34.0\%) presented with UGI bleeding. 30 patients were in Child Pugh class A, 30 in class B and 37 in class C. The most common etiology was found to be ethanol related (85.6\%) followed by chronic hepatitis B (7.2\%), unknown $(5.2 \%)$, chronic hepatitis C $(1.0 \%)$ and Non-Alocholic Steatohepatitis (NASH) related $(1.0 \%)$ as shown in table II.Out

\begin{tabular}{|c|c|c|}
\hline \multicolumn{2}{|c|}{ Variables } & n (\%) \\
\hline \multirow{3}{*}{ Age (Years) } & $<40$ & $17(17.5)$ \\
\hline & $40-60$ & $69(71.1)$ \\
\hline & $>60$ & $11(11.3)$ \\
\hline & Mean \pm SD & $50 \pm 12$ (Male: $49 \pm 11$, Female: $53 \pm 12$ ) \\
\hline \multirow[t]{2}{*}{ Sex } & Male & $81(83.5)$ \\
\hline & Female & $16(16.5)$ \\
\hline \multirow{4}{*}{ Indication of Endoscopy in COL } & UGI Bleeding & $33(34.0)$ \\
\hline & Screening & $43(44.3)$ \\
\hline & Pain Abdomen & $10(10.3)$ \\
\hline & Others & $11(11.3)$ \\
\hline Biluribin (mg/dl) -Mean \pm SD & & $2.75 \pm 3.41$ \\
\hline Albumin (g/dl) -(Mean \pm SD) & & $3.18 \pm 0.47$ \\
\hline PT (Sec. Prolonged) -(Mean \pm SD) & & $5.12 \pm 3.3$ \\
\hline \multirow{3}{*}{ Ascites } & None & $55(56.7)$ \\
\hline & Mild & $41(42.3)$ \\
\hline & Marked & $1(1.0)$ \\
\hline \multirow{3}{*}{ Encephalopathy } & None & $88(90.7)$ \\
\hline & Minimal & $7(7.2)$ \\
\hline & Advanced & $2(2.1)$ \\
\hline \multirow{3}{*}{ Child Turcotte Pugh Class (CTP) } & A & $30(30.9)$ \\
\hline & B & 30 (30.9) \\
\hline & C & 37 (38.1) \\
\hline \multirow{5}{*}{ Etiology } & Ethanol related & $83(85.6)$ \\
\hline & Chronic Hepatitis B & $7(7.2)$ \\
\hline & Chronic Hepatitis C & $1(1.0)$ \\
\hline & NASH Related & $1(1.0)$ \\
\hline & Unknown & $5(5.2)$ \\
\hline
\end{tabular}

Table II: Demographic and Clinical characteristics of study participants ( $n=97)$ 
of 33 (34.0\%) patients who has presented with UGI bleeding, 6 (6.2\%) were on CTP class A, 7 (7.2\%) patients in CTP class B and $20(20.6 \%)$ were in CTP class $C$ as shown in table III.

\begin{tabular}{|c|c|c|c|c|}
\hline \multirow{3}{*}{$\begin{array}{l}\text { Indication of } \\
\text { Endoscopy in } \\
\text { Cirrhosis }\end{array}$} & \multicolumn{4}{|c|}{ Child Turcotte Pugh Class (CTP) } \\
\hline & A & B & C & Total \\
\hline & N (\%) & N (\%) & N (\%) & N (\%) \\
\hline UGI Bleeding & $6(6.2)$ & $7(7.2)$ & $20(20.6)$ & $33(34.0)$ \\
\hline Screening & $20(20.6)$ & $16(16.5)$ & $7(7.2)$ & $43(44.3)$ \\
\hline Pain Abdomen & $4(4.1)$ & $4(4.1)$ & $2(2.1)$ & $10(10.3)$ \\
\hline Others & $0(.0)$ & $3(3.1)$ & $8(8.2)$ & $11(11.3)$ \\
\hline Total & $30(30.9)$ & $30(30.9)$ & 37(38.1 & $97(100.0)$ \\
\hline
\end{tabular}

Table III: Indication of Endoscopy in cirrhosis and its CTP Class ( $n=97)$

Out of 33 patients presenting with UGI bleeding, $6(6.2 \%)$ had small varices, $22(22.7 \%)$ had large varices with red color sign and $5(5.2 \%)$ had large varices without red color sign as shown in table IV. Out of 97 patients, 25 had small varices, 50 had large varices with red color sign, 20 had large varices without red color sign and two were without varices.

In CTP class A, there were total 30 patients. Out of them 19 had small varices, 2 had large varices with red color sign, 7 had large varices without red color sign and 2 had no varices. In CTP class $\mathrm{B}$ also there were 30 patients. Out of them 5 had small varices, 19 had large varices with red color sign and 6 had large varices without red color sign. In CTP class C also there were 37 patients. Out of them 1 had small varices, 29 had large varices with red color sign and 7 had large varices without red color sign, as shown in table $\mathrm{V}$.

\section{DISCUSSION}

Cirrhosis is the most advanced form of liver disease and variceal bleeding is one of its lethal complications. Most cirrhotic patients develop esophageal varices with lifetime incidence as high as $90 \%$. Cirrhotic patients with large esophageal varices are at high risk for bleeding. Hence, preventive efforts are concentrated on identifying cirrhotic patients with large varices. ${ }^{6}$ Present study showed that more than $90 \%$ of cirrhotic patient had esophageal varices diagnosed by UGI endoscopy. This result is much higher than the range of $24 \%-80 \%$ showed in literature. This might be due to the late presentation of the patients seeking medical attention only when they develop decompensated liver cirrhosis (CTP class B and C).

In this study, mean age of the patient was 50 years. In male mean age was 49 years and in female mean age was 53 years. Similar observation was made by Sagnelli $\mathrm{E}$ et al. ${ }^{8}$ in which mean age in male was 52.9 years and in female 58.7 years. Likewise, the mean age in the study done by Zainab $S$ et al. ${ }^{9}$ was 46.79 years, Shekar GC et al. ${ }^{10}$ was 43.18 years, Thapa P et al. ${ }^{11}$ was $41.4+11.7$ years.

In this study, $83.5 \%$ were male and $16.5 \%$ were female showing male predominance. Similarly, Thapa $\mathrm{P}$ et al. ${ }^{11}$ (male -86\%), Zainab S et al. ${ }^{9}$ (male $-60.5 \%$ ), Shekar $\mathrm{GC}^{10}$ et al (male $-78 \%$ ), Sumon $S$ et al. ${ }^{12}$ (male - $73 \%$ ) and Mukherjee P et al. ${ }^{13}$ (male73\%) showed male predominance in their study.

\begin{tabular}{|l|c|c|c|c|c|}
\hline $\begin{array}{l}\text { Indication of } \\
\text { Endoscopy in }\end{array}$ & Small & $\begin{array}{c}\text { Large with } \\
\text { Red Color Sign }\end{array}$ & $\begin{array}{c}\text { Large without } \\
\text { Red Color Sign }\end{array}$ & None & Total \\
\hline UGI Bleeding & $6(6.2)$ & $22(22.7)$ & $5(5.2)$ & $0(0.0)$ & $33(34.0)$ \\
\hline Screening & $13(13.4)$ & $19(19.6)$ & $9(9.3)$ & $2(2.1)$ & $43(44.3)$ \\
\hline Pain Abdomen & $5(5.2)$ & $3(3.1)$ & $2(2.1)$ & $0(0.0)$ & $10(10.3)$ \\
\hline Others & $1(1.0)$ & $6(6.2)$ & $4(4.1)$ & $0(0.0)$ & $11(11.3)$ \\
\hline Total & $25(25.8)$ & $50(51.5)$ & $20(20.6)$ & $2(2.1)$ & $97(100.0)$ \\
\hline
\end{tabular}

Table IV: Indication of Endoscopy in cirrhosis and association with varices $(n=97)$

\begin{tabular}{|c|c|c|c|c|c|c|}
\hline $\begin{array}{l}\text { Child Turcotte } \\
\text { Pugh Class (CTP) }\end{array}$ & Small & $\begin{array}{c}\text { Large with } \\
\text { Red Color Sign }\end{array}$ & $\begin{array}{c}\text { Large without } \\
\text { Red Color Sign }\end{array}$ & None & Total & p value \\
\hline A & $19(19.6)$ & $2(2.1)$ & $7(7.2)$ & $2(2.1)$ & $30(30.9)$ & \\
\hline B & $5(5.2)$ & $19(19.6)$ & $6(6.2)$ & $0(0.0)$ & $30(30.9)$ & $<0.001$ \\
\hline C & $1(1.0)$ & $29(29.9)$ & $7(7.2)$ & $0(0.0)$ & $37(38.1)$ & \\
\hline Total & $25(25.8)$ & $50(51.5)$ & $20(20.6)$ & $2(2.1)$ & $97(100.0)$ & \\
\hline
\end{tabular}

Table V: Child Turcotte Pugh Class (CTP) and association with varices 
The main predictors of bleeding in clinical practices are: large vs small varices, red color sign, CTP class $C$ vs CTP class $A$ and $B$. In this study, out of 33 patients (34\%) who presented with UGI bleeding, 20 (20.6\%) were in CTP class C and 22 (22.7\%) had large varices with red color sign indicating that there is increased chances of bleeding in CTP class $\mathrm{C}$ and in those who have large varices with red color sign. This finding is similar to the study done by Merli M et a ${ }^{14}$ who showed that UGI bleeding is more common in patients having large varices with red color sign and who are in CTP class C.

In the present study, most common etiology of liver cirrhosis was ethanol related (85.6\%) followed by hepatitis B virus. Similarly study done by Shekar GC et a ${ }^{10}$ and Mukherjee P et al ${ }^{13}$ also found ethanol related as the most common etiology of cirrhosis which were $62 \%$ and $34.3 \%$ respectively. But the study done by Sumon S et al ${ }^{12}$ in Bangladesh revealed Hepatitis B virus as the most common cause which was $48.7 \%$. These differences might be due to differences in social culture, easy availability of alcohol, use of more concentrated local sprit in alcohol, etc.

In this study, out of 37 patients in CTP class C, 29 had large varices with red color sign and 7 had large varices without red color sign. Out of 30 patients in CTP class B, 19 had large varices with red color sign and 6 had large varices without red color sign. These findings show the correlation between higher grades of varices with higher Child Pugh score (CTP class B and C). Study done by Shekar GC et al. ${ }^{10}$ concluded that higher grades of varices can be predicted by CTP class B and C. Sumon S et al. ${ }^{12}$ in this study concluded that higher grades of esophageal varices is seen in more advanced class of Child Pugh class with a $P$ value 0.001 . Thapa $P$ et al. ${ }^{11}$ concluded that cirrhotic patients with higher Child Pugh scare had higher grades of esophageal varices leading to presentation with hematemesis. These findings are comparable to the present study.

\section{CONCLUSION}

The cirrhotic patients with higher Child Pugh score (CTP class B \& C) have large varices with red color sign and have more chances for bleeding. Hence, routine screening of cirrhotic patients is necessary to determine the presence of varices before the development of variceal bleeding. Prophylactic therapy if started immediately after identifying large varices will decrease the incidence of bleeding leading to reduction in the mortality rate.

\section{REFERENCES}

1. NHS Choices. Cirrhosis. Retrieved 6 October 2015.

2. De franchis R, Primignani M. Natural history of portal hypertension in patients with cirrhosis. clin liver dis 2001; 5:64563.

3. Bacon BR. Cirrhosis and its complication. In: Fauci AS, Kasper DL, Hauser SL, Longo DL, Jamenson JI, Loscalzo J, editors. Harrison's principles of internal medicine. 18 th edition. New York: McGraw
Hill; 2012, p 2598.

4. Syed VA, Ansari JA, Karki P, Regmi M, Khanal B. Spontaneous bacterial peritonitis (SBP) in cirrhotic ascites: A prospective study in a tertiary care hospital, Nepal. Kathmandu University Medical Journal (2007), Vol. 5, No. 1, Issue 17, 48-59.

5. LaBrecque D, Khan AG, Sarin SK, Le Mair AW. World Gastroenterology Organisation Global Guidelines. Esophageal varices. Jan 2014.

6. Boyer T,: Natural history of portal hypertension. In: LaBreque D, ed. Vol. 1. Clinics in liver diseases-Portal hypertension. PhiladilphiaL: WB Saunder; 1997, 31-44.

7. Spina GP, Arcidiacono R, Bosch J, et al. Gastric Endoscopic features in portal hypertension: final report of a consensus conference, Milan, Italy, September 19,1992. J Hepatol 1994;21(3):461-467.

8. Sagnelli E, Stroffolini T, Sagnelli C, Pirisi M, Babudieri S, Colloredo G, Russello M, Coppola N, Gaeta GB, Cacopardo B. De Luca M, Almasio PL. Gender differences in chronic liver diseases in two cohorts of 2001 and 2014 in Italy. Infection (2018) 46:93-101 https://doi.org/10.1007/s15010-017-1101-5.

9. Zainab S, Qureshi HJ, Bukhari SMR. Study of Etiology and Prevalence of Esophageal Varices in Patients of Liver Cirrhosis. P J MHSVOL. 6 NO. 2 APR - JUN 2012, 459-62.

10. Shekar GC, B.Balaji, Shekar VC, P.Sammaiah, R.Kathyayani, Kishan B. Study of non-invasive predictors of oesophageal varices in chronic liver disease. Int. J. of Res. in Pharmacology \& Pharmacotherapeutics Vol-5(1) 2016, 53-65.

11. Thapa PB, Maharjan DK, Tamang TY, Shrestha SK. Clinical correlation between Child Pugh's score and oesophageal varices in upper gastrointestinal endoscopy in cirrhotic patient. Journal of Kathmandu Medical College, Vol. 4, No. 4, Issue 14, Oct.-Dec., 2015, 135-39.

12. Sumon S, Sutradhar SR, Chaudhary M, Khan N. Relation of different grades of esophageal varices with Child-Pugh classes in cirrhosis of liver. Mymensingh Medical Journal, 2013, 22(1):37-4.

13. Mukherjee PS, Vishnubhatla S, Amarapurkar DN, Das K, Sood A, Chawla YK, Eapen CE, Boddu P, Thomas V, Varshney S, Hidangmayum DS, Bhaumik P, Thakur B, Acharya SK, Chowdhury $A$. Etiology and mode of presentation of chronic liver diseases in India: A multi centric study. PLoS One. 2017, Oct 26;12(10).

14. Merli M, Nicolini G, Angeloni S, Rinaldi V, De Santis A, Merkel C, et al. Incidence and natural history of small esophageal varices in cirrhotic patients. J Hepatol 2003;38:266-272. 